\section{El Malestar}

en la cultura:

De la vigencia

de Freud en la

Modernidad

Johny Azofeifa*

\section{RESUMEN}

El presente trabajo tiene como objetivo enfatizar la relevancia del inconmensurable aporte del creador del psicoanálisis Sigmund Freud en la comprensión crítica y reflexiva de ese periodo tan significativo para la historia humana, como es el de la Modernidad. Para ello, de manera general $y$ divulgativa, nos abocamos a revisar algunos temas y valoraciones sobre una de sus mayores obras: El Malestar en la cultura.

\section{PALABRAS CLAVE}

Imagen de Sigmund Freud, cultura, civilización, temas fundamentales, valoraciones, psicoanalisis, modernidad.

* Licenciado en Filosofía por la Universidad de Costa Rica. Profesor de la Escuela de Estudios Generales de la UCR y de Estudios Generales de la Escuela de Ciencias Sociales y Humanidades de la UNED. (Q.D.E.P.).

\section{ABSTRACT}

The following investigation emphasizes the relevance of the magnificent approach given by the creator of the psychoanalysis, Sigmund Freud. This approach improved the cultural and reflexive comprehension of that period so significant for human history like it is know in Modern Times. To do so, in a general descriptive way, we will revise some topics and issues about one of this mayor works Civilization its Discontents.

\section{KEYWORDS}

Sigmund Freud image, Culture, Civilization, Main Topics, Reviews, Psychoanalysis, Modern.

¡Hijo de analisio,

Freud, divina llama!

Tú no precisas homenajes:

sabes bien de tu fama.

Tu genio está mal dirigido Creemos a fines de inhibidos, pero si te queremos reprimir, violamos el principio de placer.

¡Deja en paz la libido;

Aunque muchos son hoy

los que viven sin temor y lo deben a Freud.

Todos los hombres de bien te aclaman, y con sus voces saludan a coro en $t i$ al Caballero de la Neurosis.

(Poema aparecido en un diario Vienés en los años 30's)

Rec. 12-9-08 Acep. 16-9-09 


\section{ESPIGA}

INTRODUCCIÓN

Qué cosa es esa de la Modernidad? Un intento de caracterización.

Es diagnóstico ampliamente conocido el que las tres más famosas versiones conocidas de los llamados padres de la ciencia social "los clásicos", respecto a la comprensión de los aspectos cruciales de la llamada modernidad, ellos enfatizan su complejidad y multidimensionalidad que requiere ser hoy; -a principios del siglo XXIabordado desde varios ángulos $\mathrm{y}$ perspectivas.

En efecto, los tres paradigmas del pensamiento clásico más importantes y aceptados dentro del pensar social representados por -sirviéndonos de la atinada expresión de Ricoeur serían los otros "maestros de la sospecha"-Marx, Durkheim y Weber-, constituyen los esfuerzos más denodados por comprender y sancionar este rico y siempre debatido tema de que constituye el fenómeno de la modernidad.

Cada uno, según sus particulares intereses, destaca un ángulo distinto. Para Marx lo que está en la base de la modernidad es el surgimiento del capitalismo y de la burguesía revolucionaria, lo que lleva a una expansión sin precedentes de las fuerzas productivas y a la creación de un mercado mundial: la globalización tan llevada y traída hoy.

A juicio del teórico chileno Jorge Larraín, las transformaciones que la modernidad (los últimos cuatro siglos) ha producido se traducen en los logros de la burguesía revolucionaria que, al decir del padre del socialismo científico, puso fin a todas las relaciones idílicas, patriarcales y feudales, que sustituyó las relaciones personales feudales por el nexo del dinero, que ahogó los fervores religiosos, los entusiasmos caballerescos y los sentimentalismos filisteos con el agua de los cálculos egoístas, que resolvió el valor de la persona en el valor de cambio, que en lugar de las numerosas libertades reconocidas públicamente estableció la libertad de comercio, que despojó de su halo a todas las ocupaciones honorables, que arrancó de la familia su velo sentimental y que no puede vivir sin revolucionar constantemente los instrumentos de producción.

En Durkheim, aunque el punto de partida es igual que el de Marx, la sociedad feudal destaca menos el surgimiento de la burguesía como nueva clase revolucionaria y casi no se refiere al capitalismo como 
el nuevo modo de producción implementado por ella. El impulso fundamental de la modernidad es más bien el industrialismo acompañado por las nuevas fuerzas científicas. Estos dos elementos no solo lograron destruir el viejo orden sino que además, bajo su influencia, un nuevo orden social comenzó lentamente a surgir en el seno de la sociedad antigua.

Este nuevo orden tiene la ventaja sobre el anterior de ser pacífico y no militar; promover la industria que ofrece a las naciones medios para llegar a ser ricas y poderosas y reemplazar las enseñanzas de los sacerdotes por la superioridad demostrada de las proposiciones científicas. Como a la larga ninguna sociedad puede ser estable si contiene elementos contradictorios e incoherentes, Durkheim pensaba que "las sociedades modernas sólo conseguirían un equilibrio completo cuando se organicen puramente sobre una base industrial. (Larraín, 1996, 18)

En su justamente célebre Economía y Sociedad, Weber señala cómo la modernidad aparece en estrecha asociación con los procesos de racionalización y desencantamiento del mundo. Estos procesos implican "que no hay fuerzas misteriosas incalculables que entren a jugar, sino que uno puede, en principio, dominar todas las cosas por medio del cálculo. Esto significa que el mundo se ha desencantado. Uno ya no necesita más el recurso a los medios mágicos para dominar o implorar a los espíritus, como lo hacía el salvaje para quien tales poderes misteriosos existían. Sin embargo, los procesos de racionalización y desencantamiento eran concebidos por el llamado Marx burgués como fenómenos milenarios en la historia de la humanidad y no sólo como ocurrencias típicas de Occidente. Por lo tanto, la pregunta sobre su relación con la modernidad era para Weber más especifica y tenía que ver con la forma especial de racionalización que sólo se había dado en Occidente con valor y significado universales.

Por eso, el maestro alemán admite que sólo en Occidente se da la ciencia que reconocemos como válida y que también allí el arte y la arquitectura adquieren características únicas. Sin embargo, lo que caracteriza la modernidad por sobre todo es la racionalización que penetra las organizaciones humanas constituyendo las burocracias: la "jaula de hierro" en su atinada expresión. 


\section{ESPIGA}

Vemos entonces como, que además de industrialismo, capitalismo y racionalización, sea necesario agregar otras dimensiones. El término "moderno" puede definirse también como una forma de autoconciencia, con un modo específico de vida y como una experiencia vital. Por un lado, ha sido frecuentemente usado para expresar la conciencia de una época que se considera nueva en relación con un pasado antiguo e inmóvil. Lo moderno no respeta su propio pasado y se mira a sí mismo como el resultado de una transición de lo tradicional a lo nuevo.

La edad moderna se define a sí misma como el reino de la razón y de la racionalidad, que han desplazado a la religión, a los prejuicios y supersticiones, a las costumbres tradicionales. De allí nace en ella el sentimiento profundo de confianza en sí misma, de superioridad tanto con respecto al pasado como con respecto a otras sociedades donde todavía no ha llegado. Esta fe en sus principios y en la superioridad de su propio modo de vida, de acuerdo con Bauman (el sociólogo alemán de moda Y.A.S), lleva a la elite intelectual europea a considerarse un punto de referencia para la interpretación de la historia, medida de otras formas de vida que pare- cen inmaduras, incompletas, subdesarrolladas o inferiores" (Larraín, 1996, 19)

Por supuesto, -señalemos- siguiendo en esto al mayor pensador de esta época, el padre del Idealismo alemán, Jorge Guillermo Federico Hegel: el grado de autoconciencia de la modernidad no se adquiere de súbito sino que va evolucionando históricamente. Para un autor de moda M. Berman, a quien sigue el mencionado Larraín; la clasificación tiene tres etapas:

Una primera: desde principios del siglo XVI hasta el final del siglo XVII, los niveles de conciencia son bajos. Aunque los primeros escritos que muestran una conciencia acerca de la modernidad como algo nuevo en oposición a la sociedad feudal comienzan muy temprano, -por ejemplo en la obra de autores tan relevantes como-: el genial secretario florentino Maquiavelo, Rousseau, Bacon y Descartes, en general estos autores todavía luchan por encontrar el vocabulario adecuado y por expresar una realidad que aun no comprenden plenamente.

La segunda fase, a partir de la ola revolucionaria de fines de siglo dieciocho, cubre todo el siglo die- 
cinueve. En este periodo el público comparte la experiencia de vivir una época nueva y revolucionaria. La idea de modernidad recibe su formulación definitiva a partir del discurso ilustrado del siglo de las luces que destaca las ideas de ciencia, progreso y razón:

El mundo medieval poseía una visión del mundo religiosa y metafísica de carácter unificado, que expresaba una racionalidad objetiva. La modernidad cultural que trae la Ilustración, por el contrario, es un intento por desarrollar la ciencia, la moral y el arte como tres esfuerzos autónomos o esferas de acuerdo a su lógica interna. Habermas sostiene que Hegel fue el primer filosofo que desarrollo un concepto claro de modernidad en cuanto hablo de ella, en un contexto histórico, como de edad nueva". (Larraín, 1996, 20)

La tercera fase, que recién terminamos o estaremos atravesando -esa es la discusión que hoy tenemos en los círculos académicos- en el siglo $X X$, presencia la expansión de los procesos modernizadores a todo el mundo, con el consecuente desarrollo de una conciencia universal acerca de dicho proceso modernizante.
Por otro lado, siguiendo el excelente estudio del mencionado Larraín, señalemos cómo el concepto de modernidad se refiere también a un modo de vida y de organización social que surge en Europa en el siglo XVI y se expande subsecuentemente por todo el mundo conocido. Este modo de existencia combina valores y prácticas conformadoras (disciplinantes Foucault dixit) del modo de vida occidental que hoy enajenadamente nos tiene al borde de la extinción del planeta: la democracia con el industrialismo, la educación generalizada con la cultura de masas, los mercados globales con las grandes organizaciones burocráticas. Esta edad nueva, denominada modernidad, tiene algunas discontinuidades fundamentales con el pasado:

Hay que señalar en primer lugar que una de las características filosóficas principales de la modernidad es que sitúa al ser humano en el centro del mundo, lo erige en la medida de todas las cosas, en contra de la visión del mundo teocéntrica que prevalecía en la Edad Media. El ser humano pasó a ser "el sujeto", la base de todo conocimiento, el señor de todas las cosas, el punto de referencia necesario de todo lo que sucede. El mundo deja de ser el orden creado por 


\section{ESPIGA}

Dios y pasa a ser "naturaleza", con una lógica propia y autónoma que el sujeto debe controlar. De allí el interés de los pensadores ilustrados por desarrollar la ciencia y la razón de acuerdo a su lógica interna, liberada de la tutela religiosa. De allí también su irrestricta confianza e interés en una educación secularizada y autónoma que actué como agente difusor y transmisor de la ciencia, la moral y el arte". (Larraín, 1996, 20)

Un segundo tipo de discontinuidad dado por el acelerado ritmo de cambio que caracteriza a las sociedades modernas, en lo que parte resulta de la separación del espacio y el tiempo y en parte también del desarrollo autónomo de la ciencia, el arte y el derecho.

Un tercer aspecto novedoso es el ámbito ampliado de los procesos de cambio: la modernidad acelera el proceso de interconexión entre diferentes áreas del mundo y por eso los procesos de cambio tienden a ser globales.

Por último las instituciones típicas de la modernidad son también específicas y distintas. Podemos enumerar las siguientes: en lo político, el surgimiento de las naciones-estado y de formas democrá- ticas de gobierno; en lo económico: la formación de la economía capitalista mundial, el surgimiento de la industrialización y de los mercados y el crecimiento de las grandes organizaciones y sistemas burocráticos de administración; en lo social: la formación de clases y el surgimiento de la división avanzada del trabajo, y en lo cultural: el surgimiento de la educación universalizada y de una cultura secular y de masas, crecientemente controlada por los medios de comunicación o más bien de incomunicación masiva.

Pero la modernidad -enfaticémloes también una experiencia vital. El surgimiento de la modernidad se asocia con una experiencia de movilidad y cambio social, con un sentido de lo dinámico y contingente. La modernidad expresa, por un lado, una conciencia aguda de lo efímero y transitorio, de lo contingente y fragmentario.

El énfasis simultáneo en el cambio y en el poder irrestricto de la ciencia se manifiesta en la persecución de un mejoramiento e innovación incesantes propios de una relación con la naturaleza y la sociedad liberada de toda prescripción sagrada de cómo debe ser el mundo 
La experiencia vital de lo efímero y de lo contingente -para decirlo con el famoso dictum marxista: -“Todo lo sólido se desvanece" - se agudiza en períodos de aceleración del cambio y de crisis hasta el punto de que la realidad puede empezar a vivirse como caos y que sentimientos de desorientación y fragmentación se apoderan de los individuos. Estos sentimientos, fruto de una radicalización y exacerbación de la experiencia vital de la modernidad, llevan a algunos autores -sobre todo de los centros dominantes del imperialismo- a plantear el surgimiento de una nueva época de la historia: la llevada y traída Postmodernidad:

La imagen del mago evoca tanto el sentido maravilloso de sus poderes y potencialidades como el terror a un mundo demónico (sic) que se vuelve incontrolable. Es esta idea la que está detrás de esa dualidad de la modernidad que, al decir de Berman, "nos promete aventura, poder, alegría, crecimiento, transformación de nosotros mismos y del mundo y, al mismo tiempo, nos amenaza con destruir todo lo que somos, todo lo que sabemos" (citado Larraín, 1996, 23).
Terminemos este apartado de nuestro artículo, donde hemos tratado de dar una somera caracterización de este fenómeno tan complejo y paradójico de la modernidad con el acertado dictamen marxista sobre el mismo. En efecto, esta ambigüedad fundamental de la modernidad adquiere importancia con Marx. La rebelión de las fuerzas productivas desemboca en crisis periódicas que crecientemente amenazan la existencia de la sociedad burguesa. $Y$ en estas crisis, son destruidos muchos de los productos y de las fuerzas productivas mismas. De allí que Berman sostenga que en el Manifiesto Comunista Marx establece la polaridad que va a animar y dar forma a la cultura del modernismo del siglo venidero:

El tema de los deseos e impulsos insaciables, la revolución permanente, el desarrollo infinito, la perpetua creación y renovación en cada esfera de la vida; y su antítesis radical, el tema del nihilismo, la destrucción insaciable, el aniquilamiento y consumo de vida, el corazón de la oscuridad, el horror. Marx muestra cómo ambas posibilidades humanas están infundidas en la vida de cada hombre moderno por los impulsos y presiones de la economía burguesa". (Larraín, 1996, 24) 


\section{ESPIGA}

\section{El inconmensurable} aporte de Sigmund Freud al entendimiento de la modernidad

Como bien ha señalado recientemente el filósofo italiano Remo Bodei, ninguno de cuantos hemos respirado el ambiente intelectual del fenecido siglo XX podemos sustraernos a la obligación (o a la fascinación) de entendérnoslos con el psicoanálisis. Tal saber se ha difundido invadiendo terrenos situados más allá de los límites específicos de la disciplina, convirtiéndose en una coiné o lengua franca que se utiliza para interpretar múltiples fenómenos, sea en el ámbito de las ciencias humanas (suaves), sea en la frontera entre éstas y las ciencias naturales (duras):

Ocurre con frecuencia que las teorías se distancian del sentido común para luego mezclarse nuevamente con él, tal vez para quedar allí atrapados. Hoy está de moda hablar mal del psicoanálisis, sobre todo en Estados Unidos, donde se produce un proceso de negación de los fundamentos de la teoría freudiana (con el ataque politically correct a la hipótesis de que los abusos sexuales en la infancia son generalmente considerados resultado de fantasías infantiles y no datos incontrastables de hechos reales registrados por la memoria). Las razones del reciente descrédito del psicoanálisis son sin embargo múltiples: la mala práctica de algunos de sus adeptos; las temerarias derivas teóricas a las que ha estado expuesto, cuando ha sido utilizado como passepartout; su no infrecuente transformación en un (caro) taller de reparación del alma. Pero el psicoanálisis está pagando también, paradójicamente, por su propio éxito: venciendo anteriores resistencias, se ha convertido en parte integrante de nuestra cultura, que lo ha interiorizado y metabolizado, proporcionándonos beneficios enormes que tendemos a olvidar". (Bodei, 2006, 6)

Acertadamente enfatiza el suscrito comentarista, que si bien no se puede asegurar cuándo volverán los días gloriosos de la teoría y la terapia psicoanalíticas, ya hemos absorbido e incorporado lo más valioso del psicoanálisis. Freud -y con él, en diversa medida, Jung, Klein, Bion, Winnicot, Lacan, o más recientemente los frankfurtianos- se ha convertido a pesar de todo en un clásico. En su producción científica, y sobre todo hermenéutica, que si bien ha agotado la capacidad subversiva de sus inicios, hoy descubrimos necesa- 
riamente partes que han quedado caducas. Pero también, a un siglo o muchos decenios de distancia, continúan produciendo, por germinación, nuevas ideas. Porque, justamente, los clásicos se parecen a viejos árboles que, una vez podados, vuelven a florecer en todas las estaciones. Pero el mérito, también y sobre todo, corresponde a quien desarrolló y renovó el psicoanálisis y a quien todavía, con esfuerzo y resultados a veces excelentes, continúa renovándolo.

Premonitoriamente este diagnóstico contemporáneo lo tuvo muy en cuenta desde su Viena natal a finales del siglo XIX, el genial creador de uno de los paradigmas fundamentales para entender $y$ diseccionar los complejos sucesos y problemáticas de nuestras atribuladas y enfermizas sociedades modernas y ya casi cuasi postmodernas: Sigmund Freud.

Efectivamente, en el opúsculo Para la historia del movimiento psicoanálitico (1914) Freud escribió: "El psicoanálisis es (...) una creación mía." Esta "nueva ciencia" creada por Freud y (combatida al principio por la mayoría, y aún hoy por bastantes) se hallaba destinada a ejercer una enorme influencia a la vuelta de pocas décadas, un influjo cada vez más notable sobre la imagen del hombre, de sus actividades psíquicas y de sus productos culturales. No existe hecho humano que no se encuentre afectado y transformado por la doctrina psicoanalítica: el niño se convierte en un "perverso poliforme"; el "pecaminoso" sexo de la tradición se coloca en primer plano, con objeto de explicar la vida normal $\mathrm{y}$, sobre todo, las enfermedades mentales; el "yo" y su desarrollo se enmarcan dentro de una nueva teoría; las enfermedades mentales se afrontan apelando a técnicas terapéuticas antes impensadas; los hechos del tipo de los sueños, los actos fallidos, los olvidos, etc. -considerados por lo general como hechos extraños, pero irrelevantes para la comprensión del hombre-se vuelven instrumentos que sirven para contemplar la profundidad humana; fenómenos como el arte, la moral, la religión e incluso la educación se ven iluminados por una luz que todavía hoy -inicios del siglo XXI- muchos califican de "perturbadora":

Las costumbres se modifican debido a su choque con la teoría psicoanalítica, y los términos fundamentales que ésta utiliza (complejo de Edipo, represión, censura, sublimación, inconsciente, "superyó", transferencia, 


\section{ESPIGA}

etc.) son ya parte integrante del lenguaje ordinario y -para bien o para mal, con más o menos propiedad, con razón o sin ellaconstituyen herramientas interpretativas del desarrollo más global de la existencia humana. (Reale y Antiseri, 1988, 805)

Médico. psiquiatra, filósofo, iniciador e instigador de un movimiento cultural de difícil y enormes delimitaciones, Freud judío (como no) nacido en Moravia, la antigua Checoslovaquia en 1856 y muerto en Londres en 1939 está directamente presente con sus artículos y obras, y su influjo se siente en múltiples aspectos de la cultura y de la vida contemporánea. Al decir de Ricoeur sería uno "de los maestros de la sospecha" junto a Marx y Nietzsche develadores de los secretos de la sociedad moderna. Su peso e influencia van más allá del ámbito de los especialistas, invadiendo y transformando la cultura literaria, filosófica, antropológica y política de Occidente, en particular después de 1920.

Biográficamente, nos parece interesante señalar que en una investigación reciente, acerca de los libros que Freud se llevó a su exilio en Londres, en castellano figura un único autor que tuvo una rela- ción personal con el creador del psicoanálisis: el peruano Honorio Delgado, psiquiatra e introductor del psicoanálisis en su país. Delgado fue un gran germanófilo que hablaba alemán y visitó a Freud en Viena en 1923. Su libro Sigmund Freud (1926) cierra con la siguiente evocación de su encuentro con el maestro -el único testimonio sobre el encuentro de Freud con un latinoamericano-:

Para concluir, resumiremos en algunas palabras nuestra impresión personal del maestro. Figura esbelta, fina, ligeramente encorvada. Sus movimientos no son del todo fáciles; se nota la influencia de los años. La fisonomía, morena, de rasgos nobles, textura delicada: se ve el espíritu vigilante que anima y consume. Revela muchos dolores pasados y acaso cierta tristeza. La mirada es penetrante: esos ojos tienen toda la potencia acumulada de miles de años de voluntad dominadora, de ascetismo inmemorial, que han debido ponerse a prueba infinitas veces para lograr imponer a los hombres el fruto de su creación, como el héroe mitológico que solo a costa de cruentas hazañas llega a la posesión de su legítimo dominio...En conjunto, el semblante, sin ese sello de extrema austeridad que se muestra en la más conocida de sus 
fotografías, obliga a reverencia e invita a la cordialidad. Viéndole, ocurrió a mi mente, impresionándome el parecido, la imagen del "Séneca" de Rubens, de la pinoteca antigua de Munich. (Gallo, 2006, 20)

En este retrato cálido y agradecido del discípulo lejano, la personalidad de Freud:

Impresiona muy gratamente, sin hacer él lo mejor por lograrlo. ¿Qué sencillez, qué bondad! Esto es lo que más me ha impresionado, mejor dicho, conmovido, al hallarme ante el ímpetu de la vida, sin vértigo, sin parpadeo, sin vacilar un momento, con soberana lucidez, mirando hacia atrás, y que, marchando en contra de la corriente, ha remontado el curso hasta sus fuentes, espantable criadero de monstruos.

Cuando le pregunté sobre su salud, repúsome que no iba bien. "Es natural -replique- ¡con tanta labor!” “¡Oh! Exclamó- con la guerra todo lo hemos perdido y hay que trabajar mucho!" Sin embargo, la nota dominante de su persona es, a no dudarlo, la serenidad. La grandeza espiritual y afectiva de este hombre de genio, es comparable a su fuerza mental -de ello tenemos pruebas-.
(...) Por algo ha dicho el mismo Freud: "Es una pesada tarea la de tener por paciente al género humano íntegro". (Gallo, 2006, 21)

La conciencia de la presencia de una vida psíquica que no es del todo controlable por la todopoderosa razón, presencia de lo inconciente, no se expresa sólo en el uso de criterios fútiles que han entrado a formar parte del lenguaje cotidiano, como los relativos al lapsus significativo o al olvido no casual, sino sobre todo en las formas de la introspección por las que todos estábamos condicionados, en una mayor atención a las dinámicas impersonales no conscientes de la vida afectiva, en una dimensión psicológica de la pedagogía, en el mismo modo de vivir la vida erótica.

En este sentido la presencia de Freud, y por tanto del psicoanálisis, en la autoconciencia de lo cotidiano, en forma indirecta o mediata, en la cultura alta y en la mediana, pasa de los ámbitos restringidos de los especialistas a los más populares. Pero se trata también de una presencia directa, con sus escritos y con su nombre, con ese nombre simbólico del Padre Freud en las estrategias políticas de la iniciativa privada: 


\section{ESPIGA}

Como escritor resulta fascinante y seductor y no está considerado un autor difícil, sino que puede ser disfrutado por cualquiera y de hecho se dirige a cualquiera. Sus reflexiones no están dirigidas en principio a los especialistas, sino a la mayoría de la clase burguesa culta. Y la burguesía ha sido transformada por él. Después de Freud la burguesía ya no fundamenta sus propias certezas y su propia legitimación en una investidura de carácter religioso (el alma como huella vital de la trascendencia, fuente continua y misericordiosa de una identidad inatacable) ni tampoco en el mecanismo de autolegitimación racional que por un tiempo creyó que podía ser el espejo de su identidad: esperanza de un momento de máxima expansión colonial y máxima confianza en la ciencia, cuando la idea de progreso, como luz que avanza lentamente en el tiempo y en los espacios geográficos, parecía asegurar en el hombre europeo la certeza serena de estar en lo justo. (Jervis, 286)

De manera implacable e intempestiva, el padre del psicoanálisis contribuyó a destruir definitivamente la legitimación religiosa y también la ilusión de la autotransparencia victoriana. Después de
Freud el burgués no puede ya creer identificarse con su propia buena voluntad: no se legitima ya según el modo de presentarse. Sabe que existe una contradicción, y quizá un abismo, por debajo de las apariencias; no puede pretender convencer ni convencerse de que todos sus actos son buenos, expresados con buena fe o confirmados por su éxito. En otras palabras, al igual que los maestros de la sospecha citados anteriormente, Freud retoma, ejemplariza y sistematiza una duda, una grieta en la autocomplacida autoconciencia moderna: retoma y acentúa una crisis. Nos demuestra que el individuo burgués -liberal-, que el hombre occidental no sabe verdaderamente por qué actúa de un cierto modo: contra veinte siglos de pretendido racionalismo; la clave de las acciones humanas no está en su justificación moral oficial y no puede ser aprehendida directamente con una buena voluntad introspectiva que aparece, ahora, con ribetes -para citar la famosa expresión de otro maestro de la sospecha del siglo que acaba de fenecer, J.P. Sartre mala fe-.

En justicia, el maestro vienés es un racionalista crítico: el psicoanálisis no es la psicología de la crisis, es un instrumento de dominio de la 
racionalidad sobre la psique. La misión del analista, según Freud, no es poner en tela de juicio el modo de actuar burgués, sino proporcionar a la conciencia un nuevo instrumento que asegure una mejor operatividad. En el centro del pensamiento freudiano, en palabras del teórico italiano G. Jervis, hay una hipótesis fundamental:

No existe civilización ni progreso sin la utilización social de las energías instintivas individuales, que es al mismo tiempo represión del empuje personal dirigido a obtener a cada instante el máximo placer. Si es cierto que el precio de esta represión es la neurosis de todos, también es cierto que el sufrimiento manifiesto es el resultado de un desconocimiento de los propios mecanismos represivos que coincide con una mala gestión de la energía instintiva. La misión indicada por Freud consiste en abrir nuevos caminos, a través de los cuales la energía instintiva pueda doblegarse a las exigencias de lo social sin perder su propio vigor, ni dirigirse contra sí misma, con el fin de producir el máximo de operatividad y de cultura con el mínimo de sufrimiento"(Jervis, 1985, 287)
Podemos asegurar, por nuestra parte que, contrario a percepciones trasnochadas como las del positivismo o como las popperianas, la ciencia psicoanalítica, más allá de sus aplicaciones terapéuticas, es una forma de autoconciencia crítica, de hermenéutica, no una forma de autocompasión. Freud fue -al modo socrático- un moralista riguroso, extremadamente exigente hacia sí mismo y no menos severo hacia los demás, fuertemente motivado para la productividad intelectual y el crecimiento y afirmación del movimiento psicoanalítico, poco tolerante de disidencias, decididamente negativo respecto a la posibilidad de transformación político-social, hostil hacia los nacientes movimientos socialistas, poco simpatizante con sus alumnos más jóvenes que optaban por la adhesión a la izquierda y por posiciones antinazistas. Fue hasta sus últimos días una persona de enorme estatura moral e intelectual y tuvo el don de conjugar la originalidad y la capacidad de síntesis, que son quizá las principales características del genio:

Pero el mensaje freudiano, menos rigurosamente objetivo y científico de lo que quería su fundador, es de hecho poco funcional para la razón burguesa. 


\section{ESPIGA}

Mirándolo bien, por debajo de la proclamada confianza freudiana en la razón, está presente un profundo pesimismo. No es solamente cierto aquello de que "donde estaba el Ello deberá estar el Yo", sino que también es cierto que "el Yo no es dueño de su propia casa"; no es tan superable el contraste entre las exigencias instintivas y las exigencias de represión social; y no es tan fácilmente sanable la tensión que lleva a todo hombre a esperar, y a sucumbir, en las propias ilusiones. Más allá de un proyecto de integración, la idea de Freud conserva un carácter molesto (y por lo tanto revulsivo en potencia) de lo que no deja de interpelar a la conciencia sin proporcionar las respuestas seguras que quisiéramos en cada momento. (Jervis, 1985, 288)

\section{La última teoría de la civilización de Freud: un breve análisis del El Malestar en la cultura}

El psicoanálisis, en efecto, ha conseguido destapar la olla de grillos a la que se habían arrojado desordenadamente los contenidos y las formas de nuestros conflictos, de nuestras aspiraciones y nuestros deseos, revelar la maraña de efectos ambiguos que se agitan en la supuesta inocencia del niño o en el seno de la institución familiar; reivindicar el papel subversivo de la sexualidad; mostrar las vertiginosas profundidades de la psique; liberarnos, al menos parcialmente, de las angustias sin nombre que fermentan en la intersección (en la interfaz -en el lenguaje al uso-) entre conciencia e inconciente -ese nuevo continente descubierto por Freud-. El psicoanálisis nos ha enseñado -lo que no es poca cosa- a mirar (more socraticum), dentro de nosotros, a ver el alma dividida, no compacta, frágil a veces en sus delicados equilibrios:

Nos ha hecho descubrir el inconciente en un sentido dinámico; ha explicado los sueños, el chiste, las neurosis. Ha mostrado cómo, cuando educamos a nuestros hijos, el que habla o impone reglas y prohibiciones no es nuestro Yo, sino nuestro Superyó, esa figura psíquica, en parte inconciente, que es la heredera de todos los mandamientos y la suma de todas las figuras que alguna vez tuvieron influencia y autoridad sobre nosotros. Lo que significa que educamos a nuestros hijos repitiendo normas más antiguas que aquellas de las que tenemos conciencia, normas que hemos interiorizado y pertenecen a la cadena de las generaciones pasadas. Por otra 
parte, el psicoanálisis nos ha enseñado a ver -en la familia y en el individuo- un fenómeno que no deja de manifestarse: la presencia de enormes conflictos que ni la familia ni el debilitado individuo están capacitados para contener y controlar. Nos ha permitido por ello ver cómo la hipertrofia del Yo se relaciona tanto con la pérdida de la autoridad de la tradición y las instituciones, sedimentadas en el Superyó, como con la presión ya no suficientemente contenida de los deseos. (Bodei, 2006, 8-9)

Lúcidamente, el historiador de la filosofía italiano, enfatiza cómo de este modo el Yo se ha expandido y debe continuar expandiéndose para conquistar porciones de un Ello saneado, pero que se ha vuelto más débil, más indefenso, más expuesto a los ataques combinados y complementarios de las mayores exigencias de satisfacción pulsional y de la desorientación de las instancias del Superyó:

Es como si, caídas las barreras del individuo "liberal" responsable, se hubiese dado vía libre a la satisfacción de deseos que el principio de realidad lograba antes controlar, puesto que han desaparecido los frenos e inhibiciones de carácter institucional y familiar. Después del psicoanálisis, en fin, nadie puede sentirse de entrada "normal": la normalidad es un punto de equilibrio que se alcanza tras una serie de luchas internas y externas, un estado que nunca está garantizado. Estos legados del psicoanálisis, integrados en el campo más vasto de la cultura, son ya imposibles de eliminar. (Bodei, 2006, 9)

Creemos sumamente interesante, contraponer -en este momento- a esta positiva y afirmativa valoración del psicoanálisis, y en particular de la obra de Freud, esta otra opinión, -que sin duda-, nos muestra otra cara del evidentemente controversial proyecto psicoanálitico:

Despiadada escuela de egoísmo, el psicoanálisis se encarniza con el mayor cinismo contra muchachas un poco asombradas por la vida a las que transforma en unas criaturas innobles de un egocentrismo delirante, ya que sólo pueden suscitar un legítimo disgusto... Mezquindad, egoísmo, arrogante estupidez, ausencia completa de sentido moral, incapacidad crónica de amar: he aquí el retrato exhaustivo de una mujer analizada... Su psicoanálisis la transformó en una verdadera basura, sin tripas, sin conciencia... (...) cuanto más innobles sean mejor les irá... 


\section{ESPIGA}

todo un programa; pero ella iba a ponerlo en aplicación punto por punto. (Bardotti, 2007, 6)

Señalemos cómo, en la última fase de su larga y productiva vida, el padre del psicoanálisis prestó cada vez mayor atención a las cuestiones relativas a la civilización, sus raíces y su efecto en la psicología humana. Estaba particularmente interesado en determinar cómo la cultura en su totalidad ayudaba o dificultaba el ingente deseo humano por alcanzar la felicidad. Freud trató -fundamentalmente- esta problemática en dos libros muy conocidos, El porvenir de una ilusión (1927) y El malestar de la cultura (1930) y ¿Por qué la guerra? (1933).

Se ha señalado que, evidentemente, El malestar en la cultura es la expresión del pesimismo de Freud en el ocaso de su vida. Pero haría falta determinar la índole del malestar en cuestión y, por ende, el objeto del pesimismo freudiano. La crítica erudita -que nunca se siente incómoda cuando explica la obra por medio del hombre-, atribuye frecuentemente la amargura del último Freud a las vicisitudes de su vida: la imborrable marca del traumatismo que fue para él la Primera Guerra Mundial, los duelos de su familia, la defección y posterior rechazo de sus mejores discípulos, la lucha cotidiana contra el cáncer (con el cual tuvo que lidiar 16 dolorosos años y 33 operaciones) y, como telón de fondo, la crisis europea que conduciría a la Segunda Guerra Mundial y el abrupto ascenso del nazismo que finalmente lo obligará a exiliarse en el año 1939 a Inglaterra.

Contrario a estos enfoques un tanto unilaterales, por nuestra parte creemos que la explicación de un texto se encuentra en él mismo. En este sentido, El malestar en la cultura indicaría un punto en el cual el descubridor del psicoanálisis, después de alcanzar una meseta en su elaboración teórica, se vuelve y contempla el horizonte que se despliega a sus espaldas desde la atalaya de sus últimos trabajos. Para tener una medida de esta obra, conviene entonces inscribirla en la corriente de un pensamiento en perpetuo devenir, que nunca dejó de construirse contra sí mismo, carácter que explica su tensión, contenida por un estilo de sencillez clásica pero perceptible a la distancia de sus más de setenta años de escrita.

Su discípulo (uno de los pocos que lo siguieron hasta el final) y más famoso biógrafo Ernest Jones, nos 
brinda una vivida presentación de dicho texto:

En 1929 Freud reanudó su actividad literaria y escribió otro libro. Comenzó a hacerlo en julio y terminó el primer borrador al cabo de un mes más o menos. El título que en un comienzo le quiso poner era Das Unglück in der kultur (La desdicha de la cultura), pero luego lo cambio por Das Unbehagen in der kultur (El malestar en la cultura). Unbehagen fue una palabra para nosotros de difícil traducción, puesto que el término inglés más apropiado "dis-ease" (desazón) resultaba anticuado. El propio Freud sugirió "Man's Discomfort in Civilization" (El desasosiego del hombre en la civilización), pero finalmente se tituló Civilization its Discontents (El descontento en la civilización) -en la versión castellana El malestar en la cultura)-. En el plazo de un año se agotó por completo la edición de 12.000 ejemplares, y hubo de reeditarse. No obstante el mismo Freud quedó muy insatisfecho por el libro. Así lo notificó a Lou Andreas Salome: "Su acostumbrada perspicacia le habrá hecho suponer por qué he demorado tanto la respuesta a su carta. Ya le ha dicho Anna que estoy escribiendo algo, y hoy he terminado la última frase, con la que -en cuanto es posible hacerlo así aquí, sin contar con una biblioteca- acaba la obra. Trata ésta de la civilización, conciencia de culpabilidad, felicidad y parecidas excelsas cuestiones, y se me antoja, a mi entender con toda la razón, muy superflua en contraposición a mis primeras obras, en las que siempre había un impulso creador. ¿Pero que otra cosa podría hacer? No puedo pasarme todo el día fumando y jugando a las cartas, no debo andar demasiado, y la mayoría de lo que hay para leer ya no me interesa. Así que me puse a escribir, y el tiempo transcurría de esta forma muy agradablemente. Al escribir esta obra he descubierto de nuevo las verdades más triviales. (Jones, 2003: 614)

Nos permitimos -en este momento- transcribir el importantísimo resumen valorativo que de esta obra realiza este significativo autor, que fue sin duda uno de los primeros que la leyó:

En El malestar de la cultura Freud hacía la más completa exposición de sus ideas en el campo de la sociología, un campo que, tal como dijo en alguna ocasión, "no puede ser otra cosa que una psicología aplicada". El libro comienza con el problema más amplio posible: 


\section{ESPIGA}

la relación del hombre con el universo. Su amigo Romain Rolland le describió una emoción mística de identificación con el universo, a la que Freud llamó sentimiento "oceánico". Sin embargo, Freud no podía hacerse a la idea de que esto fuera un elemento primario del espíritu, y lo recondujo al estadio más primitivo de la infancia, a una época en que no se establecía distinción alguna entre el yo y el mundo exterior. Freud planteaba entonces la cuestión del objeto de la vida. En su opinión este planteamiento no tenía sentido estrictamente hablando, al basarse en premisas no demostradas; como observaba, se trata de un problema que raramente se plantea respecto al mundo animal. Por tanto, se centró en la más modesta cuestión de cúal es el fin que pone de manifiesto la conducta humana. Éste le parecía sin discusión la búsqueda de la felicidad, no sólo de la felicidad en su sentido más limitado, sino también de la dicha, placer, tranquilidad de espíritu y contento: la satisfacción de todos los deseos. La vida se halla sujeta al principio placerdolor. En su forma más intensa ello solo tiene lugar como fenómeno episódico; cualquier continuación del principio del placer se experimenta únicamente como un tibio bienestar. La felicidad humana, por tanto, no parece constituir el objeto del universo, y las posibilidades de infelicidad se hallan más a nuestro alcance. Las causas de esta última son el sufrimiento corporal, los peligros del mundo exterior y los problemas de nuestras relaciones con nuestros semejantes, acaso la más dolorosa de todos ellos" (Jones, 2003, 615)

Sigue diciendo el discípulo irlandés, que moriría en 1958, dos años después de finalizar su opus magna sobre el padre del psicoanálisis:

A continuación se ocupaba de las relaciones sociales, el verdadero origen de la civilización. Éste tenía lugar merced al descubrimiento de que un cierto número de hombres que fijaban límites a su propia satisfacción eran más fuertes que un hombre solo, por fuerte que éste fuera, que se hubiera acostumbrado a gratificar sus impulsos sin restricción. "La fuerza de este cuerpo unido se contrapone como "Derecho" a la fuerza de cualquier individuo, que se condena como "fuerza bruta." La sustitución del poder de un hombre solo por el poder de un grupo unido representa el paso decisivo hacia la cultura. Su carácter esencial reside en la circunstancia de que los miembros de la comunidad han restringido sus 
posibilidades de satisfacción, mientras que el individuo no reconocía semejantes restricciones. Por consiguiente, el primer requisito de una cultura es el de la justicia, es decir, la seguridad de que, una vez establecido un orden jurídico, no será infringido en beneficio de cualquier individuo. (Jones, 2003, 615)

A continuación sigue relatando el distinguido biógrafo y uno de sus primeros discípulos:

Esta situación conduce inevitablemente a un interminable conflicto entre las pretensiones de libertad del individuo para obtener satisfacción personal y las demandas de la sociedad que con tanta frecuencia se les oponen. Entonces Freud pasaba a discutir la cuestión, tan vital para el futuro de la civilización de si era o no este conflicto irreconciliable. A este respecto fijaba una lista impresionante de restricciones que pendían sobre la vida sexual del hombre: prohibición de autoerotismo, impulsos pregenitales, incesto y perversiones; limitación a un sexo, y en última instancia a un compañero. "La vida sexual del hombre ha sido seriamente perjudicada, y en ocasiones produce la impresión de ser una función que se halla en proceso de atro- fia." Estas restricciones imponen un duro tributo en forma de neurosis generalizadas que se acompañan de sufrimientos y de la consiguiente reducción de la energía cultural disponible.

¿Por qué la comunidad civilizada no podría consistir en parejas de individuos felices ligados entre sí únicamente por intereses comunes? ¿Por qué necesita además extraer una energía que deriva de una libido cuyo fin está inhibido? Freud halló una clave al interrogante considerando el precepto "amarás al prójimo como a ti mismo" no sólo como poco práctico, sino indeseable por muchos conceptos. Esta gran carga impuesta por la sociedad tiene lugar por el fuerte instinto de crueldad agresiva del hombre. "Debido a esta primordial hostilidad entre los hombres, la sociedad civilizada se ve constantemente amenazada de desintegración. La cultura tiene que recurrir a cualquier esfuerzo que sea necesario para levantar barreras a los instintos agresivos del hombre." Esta tendencia a la agresión, que en opinión de Freud representaba el obstáculo más formidable a la cultura, es "una disposición humana innata, autónoma e instintiva. (Jones, 2003, 615) 


\section{ESPIGA}

En su valoración final, el fiel discípulo y continuador de la revolucionaria saga freudiana señala:

La forma más típica de hacer frente a esta realidad de la agresión consiste en interiorizarla en la parte del yo denominada superyó o conciencia. Ésta experimenta entonces la misma tendencia de dura agresividad hacia el yo que el yo le hubiera gustado ejercer contra los demás. La tensión entre los dos constituye lo que se llama el sentimiento de culpabilidad. Un sentimiento de culpa no procede de un sentimiento innato de pecado, sino del miedo a la pérdida del amor. Y cuando el superyó se halla firmemente constituido, entonces, el temor a la desaprobación se hace incluso más fuerte que el miedo a la desaprobación de las otras personas. La simple renuncia a un acto prohibido no libera ya a la conciencia, como bien saben los santos, porque todavía subsiste el deseo. Por el contrario, la privación, y más todavía la desgracia, intensifican el sentimiento de culpa porque se consideran como merecedores de castigo, llegados a este punto, Freud adelanta la original idea de que el sentimiento de culpa es la respuesta concreta a la agresividad reprimida. Puesto que es hasta tal extremo inconsciente, su expresión aparente constituye un sentimiento de angustia, de malestar general o infelicidad". La intención de presentar el sentimiento de culpabilidad como el problema más importante de la evolución de la cultura, señalando que el precio pagado por el progreso de la cultura consiste en la pérdida de felicidad a que se llega con el aumento del sentimiento de culpabilidad.

...El malestar en la cultura se nos presenta como el despliegue de las tesis metapsicológicas de Freud a escala de la comunidad humana, siguiendo la línea de Tótem y Tabú y Psicología de las masas y análisis del yo. Con diez años de intervalo, esos dos textos habían planteado ya, en efecto, el principio que sustenta El malestar en la cultura: que no se puede estudiar el destino del individuo por fuera del de la comunidad en la cual ésta inserto, que uno y otro son partes solidarias de una misma estructura. Situado en este contexto, El malestar en la cultura no aparece ya como un ensayo de sociología, así como Tótem y Tabú no era un ensayo de antropología: a partir de algunos materiales clínicos o míticos, reales o fantasmáticos, los dos textos articulan una lógica subjetiva cuyas conclusiones, retrospectivamente, se revelan premonitorias (Rey-Flaud, 2005, 11) 
Como hemos señalado anteriormente, a fines de la década de los veinte y principios de los treinta, Freud retoma esa empresa en tres escritos que plantean la cuestión del destino de los hombres a través del destino de las comunidades humanas: El porvenir de una ilusión (1927), El malestar en la cultura (1930) y ¿Por qué la guerra? (1933). Siguiendo el principio expuesto en el primero de estos textos, El malestar en la cultura reconstruye la filogénesis de la civilización a partir de la ontogénesis del sujeto. Esta vez, Freud parte del "sentimiento oceánico" que su amigo el escritor francés Romain Rolland propuso en calidad de fuente del sentimiento religioso. Freud da cuenta de ese "sentimiento" interpretándolo como una reminiscencia del yo-real originario, sin borde, sin temporalidad, del cual el sujetorealidad "acabado" guarda un oscuro recuerdo bajo la forma del sentimiento del infinito.

Ese estado mítico originario, figura del primer narcisismo, nos presenta un mundo en el cual no pasa nada, puesto que nada puede acontecer en ese apeiron que no ofrece al acto hito alguno de lugar o de tiempo. Freud, entonces, invierte el argumento de Romain Rolland y muestra que para el hombre la vida sólo se hace posible renunciando al narcisismo para ingresar a un mundo de límites, es decir al mundo de la castración y de la muerte. No obstante, agrega, ese renunciamiento jamás se consumará del todo pues el recuerdo del yo primordial "ilimitado" mantendrá en lo más profundo del hombre una reivindicación que ninguna represión podrá extinguir y que alimentará un odio irreprimible contra todo lo que se le presente como invocación al orden del renunciamiento. La auténtica fuente del sentimiento religioso se asienta sobre este principio: "la nostalgia por la protección del padre".

Debe hacerse notar que, al exponer este proceso, Freud se ubica en una segunda disposición que no es ya la del "yo realidad" (Real-Ich) sino la del yo-placer (Lust-Ich). Esta disposición corresponde a un momento en que el corte encarnado en la pérdida del pecho materno ya ha acaecido, y el hombre ha sido arrojado al desamparo de un mundo en el que no le queda otro recurso que apelar al Otro todopoderoso para restablecer el estado "oceánico original destrozado". La invocación al padre es, por lo tanto, una demanda de amparo dirigida a un "salvador" que podrá proteger al hombre de la castración y de la muerte, 


\section{ESPIGA}

en un mundo donde la castración y la muerte ya han acontecido" (Rey-Flaud, 2005, 26)

Siguiendo a Rey -Flaud, hagamos en este momento una pequeña $\mathrm{y}$ somera enunciación de los principales temas de la obra referida: Los dos primeros capítulos introductorios de El Malestar en la Cultura plantean la cuestión de la nostalgia del narcisismo y pasan revista a los posibles caminos de retorno a ese estado primordial; en el primer capítulo, Freud se lanza a resolver de manera psicoanalítica el verdadero valor del "sentimiento oceánico" refiriéndolo al tema del surgimiento de la actitud religiosa como sustituto del desamparo infantil- La religión sería una ilusión, una neurosis social-. En el capítulo segundo: La obra nos refiere al trabajo anterior "El Porvenir de una ilusión" -donde contrapone El Principio de Placer al Principio de Realidad- Ejes de la Economía Libidinal

A partir del capítulo III, Freud ingresa de lleno a la problemática de la civilización y se pregunta cómo se constituye la matriz del orden de la civilización. El orden de la cultura confirma que está instituido por la muerte del Otro primordial y que está consagrado por el odio al hermano. -El engaño ontológico del Otro y la rebelión del sujeto- La civilización es expresión del devenir subjetivo individual-.

El núcleo del renunciamiento al goce narcisístico que está en el origen del "malestar" que fustiga al hombre culturalizado esclarece de manera especial la represión de la sexualidad que se expone en el capítulo IV. Las limitaciones que impone la naturaleza hostil: la Ananké (el trabajo)- Devenir de Eros: "El día en que el hombre se irguió". Las metamorfosis de Eros: nacimiento del amor. Los avatares de la sublimación: la amistad y el amor por la creación entera.

Después de esta exposición sobre la génesis y las distintas declinaciones del amor, Freud aborda en el capítulo $\mathrm{V}$ lo que se resiste al mandato del amor y es fundamento del "malestar en la civilización": el odio. Arqueología del odio: el odio por lo extraño en sí mismo. El redoblamiento del odio: odio contra el Otro del lenguaje. Los "individuos dobles", la elección obsesiva. El tabaco como remedio del malestar de la civilización. "Amarás a tu prójimo como a ti mismo". El amante de la verdad. Las tres pasiones del ser humano: la indiferencia, el odio y el amor. 
En el capítulo VI, Freud expone el principio de sus últimas concepciones mito-lógicas, según las cuales la vida del hombre es producto del entrelazamiento de la pulsión de vida y de la pulsión de muerte: Eros y Tánatos. La civilización ante el enfrentamiento entre Eros y tánatos. La conquista del fuego. La Eiapopeia del cielo. El canto de la nodriza, analogon del discurso religioso, le recuerda a Freud la problemática del El Porvenir de una ilusión, desplazada, sin embargo, pues no indaga aquí la esperanza "ilusoria" sino lo que resta de esa "ilusión" y que, paradójicamente, la alimenta la culpa. Ese será el tema del capítulo VII.

En este capítulo desarrolla: Origen de la culpa y del Superyó. Acerca del enigmático origen del sentimiento de la culpa. La defensa del padre ideal. ¿Porqué defiende el hijo la figura del padre ideal?. El destino de la civilización. La función de la repetición-Ideal, ideal del yo y superyó. La pareja Eros y Ananké. No hay Eros sin Ananké. ¿Es posible desecar el Zuydersee?. ¿Es concebible una civilización mundial?. El desquite de Tánatos. Lo que encubre el amor a la humanidad. Al final, en el capítulo VIII trata el tema del eterno combate entre Eros y Tánatos. con lo que concluye de manera pesimista, la citada obra freudiana.

\section{AMODODECONCLUSIÓN}

La lucha por la liberación de la "economía libidinal" en el nuevo siglo: Podemos concluir señalando, como según Freud, lo era hace 70 años, hoy a inicios del siglo 21, en una -paradójicamente- bautizada como Edad del conocimiento: El mayor peligro para el futuro de la humanidad, es la prohibición de pensar. Y pensar significa cuestionar, interrogar, interpretar, sin asignar un sentido fijo o inmutable a las proposiciones teóricas, así como no asignamos un sentido definitivo a un síntoma o a un sueño, sin por ello dejar de buscarlo. Pero pensar significa también reconocer los límites del pensar mismo, límites que Freud recogió en el concepto de Ananké: la creencia de que todo es interpretable, la búsqueda de sentido a todo cuanto le sucede al ser humano y cuanto sucede en él, no es más que una nueva Weltanschauung que nos promete la ilusión de un saber absoluto, a juicio de un estudioso:

La estrategia de atacar el psicoanálisis poniendo en duda la historia heredada y cuestionando la figura de Freud pone en evidencia una dificultad esencial, como dice el historiador de la ciencia Frank J. Sulloway de la Universidad de Berkley (sic): "En tanto historiador de la ciencia que ha estudia- 


\section{ESPIGA}

do la vida de científicos como Copérnico, Newton y Darwin, a menudo me he encontrado con leyendas fundadoras análogas (es decir, más o menos heroicas, el científico o pensador solitario que emprende la dura lucha de cambiar la manera de pensar a una época, el hombre honesto y desinteresado sin otra ambición que la verdad). Desde este punto de vista diría sin dudarlo que nunca una leyenda de los orígenes había sido desarrollada de manera como ésta. El psicoanálisis -agrega Sulloway- es la única teoría que exige que su propia historia sea perfectamente coherente con la teoría elaborada por su inventor... Desde este punto de vista historiográfico, este género de lógica circular puede ser nefasto. Si la teoría de Freud fuera verdadera en un ciento por ciento, habría sido posible hacer una buena historia con este enfoque conceptual. Pero en tanto esta teoría es problemática lo que se obtiene es forzosamente una historia problemática, y de manera más verosímil aún, una historia complaciente y llena de defectos" (Bardotti, 2007, 6).

El juicio del citado analista italiano, enfatiza como:

El solo hecho de que se sigan discutiendo casos clínicos escritos hace un siglo es sorprendente.
Cuando nos enteramos lo conjetural de los hechos sobre los que construyeron la sorpresa es aún mayor. La incommensurabilidad de paradigmas salta a la vista ya que en el comienzo del artículo que se propone leer a Freud a la luz de los avances neurocientíficos. "Para algunos, trazar el balance de lo que queda hoy de la teoría freudiana puede parecer injusto; nadie puede esperar que una teoría formulada en el siglo XIX pueda anticipar los descubrimientos que se han producido después de ella, con los medios y conocimientos de los que ella misma no pudo disponer.

Bien mirada, la idea de que Freud construyó y no descubrió los hechos sobre los cuales basó su doctrina se dice de viva voz todos los días: al psicoanálisis no le interesan los hechos del mundo. El epistemólogo que cada psicoanalista lleva adentro dice: la teoría de la verdad como correspondencia (es decir, sostener que "la paciente tuvo fantasías de tener relaciones con su padre" es verdadero y sólo si la paciente tuvo fantasías de tener relaciones con su padre) es ideología cientificista. La paradoja es que el psicoanálisis jamás se habría podido abrir paso sin ofrecer hechos, sin ofrecer una cura, sin garantizar resultados mejores, mucho mejores que sus oponentes. (Bardotti, 2007, 7) 
Siguiendo al pensador latinoamericano Helio Gallardo, quien lúcidamente señala que el mundo pasa por una serie de cambios mundiales, que algunos bautizan como crisis de civilización, este grave acontecimiento que se expresa entre otros hechos como: la constitución irresuelta de desafíos mundiales, la intensificación de la sobrerrepresión libidinal -como ya lo anunciaba el pensamiento freudiano- y la intensificación de una polarización entre incluidos e excluidos del sistema.,-para no señalar la incontenible crisis ambiental, el rampante armamentismo nuclear, la inseguridad, codicia y empobrecimiento, y todas esas patologías sociales, que hoy aquejan a nuestras sociedadessolo podrán ser resueltas política y humanamente de un modo positivo por nuevos movimientos y movilizaciones sociales gestados en y por la crisis y cuyas acciones tengan alcance estratégico, entendido éste como prácticas que imposibiliten la reproducción económica y libidinal del actual desorden mundial y gesten $\mathrm{y}$ realicen en el mismo movimiento condiciones alternativas de existencia plenamente humanas.

Desde el punto de vista de la sensibilidad cultural, el sometimiento de las mujeres y de lo femenino ha prolongado la foca- lización genital y por ello reproductiva o natural (y sin paradoja, también pornográfica de las relaciones entre los géneros, en circunstancias que esta prolongación resulta innecesaria desde hace medio siglo. Para América Latina la focalización genital ha implicado reproducir y estimular una moral religiosa cátolica centrada en el sexo culpable y que identifica el cuerpo con el demonio y el pecado. En estas condiciones, genitalización, pecado, sexo reproductivo, y ausencia de gratificación erótica constituyen factores de una cultura libidinal determinada por impulsos violentos, agresivos y excluyentes enteramente coherentes con el fetichismo económico del consumo compulsivo (Gallardo, 2006, 7, 8).

Como ya lo anunciaba la monumental obra freudiana, en el siglo pasado, de allí su vigencia imperecedera de cara al nuevo siglo, la lucha contra la represión libidinal, esa energía pulsional descubierta por el padre del psicoanálisis, sobrerreprimida por el superyó cultural y religioso, impide a esta energía instintiva orientarse a la gratificación y al cuidado de sí, como condición de sabiduría política (Foucault). En este capitalismo salvaje y rapaz que hoy bajo el ropaje de una globalización neoliberal 


\section{ESPIGA}

domina la sensibilidad de las sociedades occidentales, esta energía se desplaza de manera agresiva y destructiva hacia objetos "exteriores" a los que destruye o adora: al "otro" y a su medio de vida ecológico en el primer caso, y el consumismo ostentoso y el sexismo desenfrenado en el segundo caso.

Las luchas de los movimientos feministas con teoría de género, principalmente, han puesto en evidencia, cómo el fenómeno de represión libidinal, históricamente como lo anunciaba proféticamente Freud, ligado a la reproducción de una cultura de la escasez y de la infelicidad, lo que produce el malestar anunciado, constituye hoy un reto impostergable, al que debemos enfrentar hombres y mujeres sin ningún miramiento; este es, sin duda alguna, el mejor homenaje que se le debe rendir al gigante del pensamiento que se llamó Sigmund Freud.

¡Lo cuenta Carl Jung en alguna parte: En su primera visita a los Estados Unidos: "Freud exclamaría mirando hacia la estatua de la Libertad en la ciudad de Nueva York: ¿No saben que les llevamos la plaga? Para bien de la humanidad, pensamos nosotros, esta plaga se ha difundido beneficiosamente. ¡Loado sea!
BIBLIOGRAFÍA

Asson, Paul Laurent. (1982). Freud La filosofía y los filósofos, Ediciones PAIDÓS, Barcelona.

Bardotti, Santiago.(2007)."Disección sobre el diván", en Semanario Universidad. San José Bodei, R. y Jervis, G. (1985). La Cultura del 900, t. 3, México: Siglo XXI editores.

Bodei, Remo (2006). "¿Qué queda de la herencia del psicoanálisis?". Revista de Occidente, Madrid, Diciembre, n. ${ }^{\circ} 307$.

Calvino, Italo (2007). "Por qué leer los clási$\cos ^{\prime \prime}$. Periódico OJO, Julio, San José.

Freud, Sigmund (1984). El Malestar en la Cultura. México: Alianza Editorial.

Gallo, Rubén (2006). “La Biblioteca Española de Sigmund Freud". Revista de Occidente, Madrid, Diciembre, n. ${ }^{\circ} 307$.

Gallardo, Helio (2007). "Cambios Mundiales" Inédito

Jones, Ernest (2003). Vida y obra de Sigmund Freud. Barcelona:Anagrama.

Larraín, Jorge (1996). Modernidad, razón e identidad en América Latina. Santiago, Editorial Andrés Bello.

Le Rider J y Rey-Flaud. (2005). Sobre El malestar en la cultura de Sigmund Freud. Buenos Aires, Ediciones Nueva Visión.

Reale, G. y Antiseri, D. (1988). Historia del Pensamiento Filosófico y Científico. T.3, Barcelona: Editorial Herder.

Tubert Silvia. (1999). Malestar en la palabra. Madrid: Biblioteca Nueva. 